\title{
Molecular Mechanisms Underlying Hypothermia-Induced Neuroprotection
}

\author{
Yasushi Shintani, Yasuko Terao, and Hiroyuki Ohta \\ Pharmacology Research Laboratories, Pharmaceutical Research Division, \\ Takeda Pharmaceutical Company Limited, 2-17-85, Jusohonmachi, Yodogawa-ku, Osaka 532-8686, Japan \\ Correspondence should be addressed to Yasushi Shintani, shintani_yasushi@takeda.co.jp
}

Received 26 August 2010; Accepted 12 October 2010

Academic Editor: Hyung Soo Han

Copyright (๑) 2011 Yasushi Shintani et al. This is an open access article distributed under the Creative Commons Attribution License, which permits unrestricted use, distribution, and reproduction in any medium, provided the original work is properly cited.

\begin{abstract}
Stroke is a dynamic event in the brain involving heterogeneous cells. There is now compelling clinical evidence that prolonged, moderate cerebral hypothermia initiated within a few hours after severe ischemia can reduce subsequent neuronal death and improve behavioral recovery. The neuroprotective role of hypothermia is also well established in experimental animals. However, the mechanism of hypothermic neuroprotection remains unclear, although, presumably involves the ability of hypothermia to suppress a broad range of injurious factors. In this paper, we addressed this issue by utilizing comprehensive gene and protein expression analyses of ischemic rat brains. To predict precise target molecules, we took advantage of the therapeutic time window and duration of hypothermia necessary to exert neuroprotective effects. We proposed that hypothermia contributes to protect neuroinflammation, and identified candidate molecules such as MIP-3 $\alpha$ and Hsp70 that warrant further investigation as targets for therapeutic drugs acting as "hypothermia-like neuroprotectants."
\end{abstract}

\section{Introduction}

Stroke is the second leading cause of death in the world [1], and is a primary cause of long-term disability in adults $[2,3]$. One potential approach for treating acute stroke involves neuroprotective agents. Although more than 100 clinical trials of potential agents have been conducted, none of these agents proved to be clinically efficacious except for a free radical scavenger edaravone [4-6]. However, recent progress in understanding the disease have unveiled the cellular and molecular events underlying ischemic cell death, such as loss of metabolic stores, excessive intracellular calcium accumulation, oxidative stress, and neuroinflammatory response. For instance, expression of stress, apoptosis, and inflammationrelated genes is known to be upregulated upon reperfusion and reoxygenation $[7,8]$.

Therapeutic hypothermia is a promising neuroprotective intervention shown to improve outcome from brain ischemia in humans. The neuroprotective role of hypothermia has been well established in experimental animals [9-11] and in patients with cardiac arrest $[12,13]$. Although the key mechanism has not been clarified, hypothermic neuroprotection may provide insight into stroke pathology and suggest novel therapeutic drug targets. To date, reactive oxygen species production [14], NF- $\kappa$ B activation [15], neutrophil infiltration [16] and cytochrome $c$ release [17] have been observed to be inhibited in hypothermia-treated ischemic brains. However, it is difficult to discern an intrinsic hallmark of hypothermia from sequential outcomes by retrospective approaches. To overcome this drawback, we performed comprehensive gene and protein expression analyses using ischemic brains with or without hypothermia collected at appropriate time points. DNA microarray and proteomic approaches are revolutionary technologies for performance of high-throughput analyses of global gene and protein expression. However, additional devises are needed to elucidate the essential molecules and to identify appropriate targets for therapeutic intervention from massive amount of expression profiles. In this series of study, we focused on the therapeutic time window and duration 
Establishment of a brain temperature control system

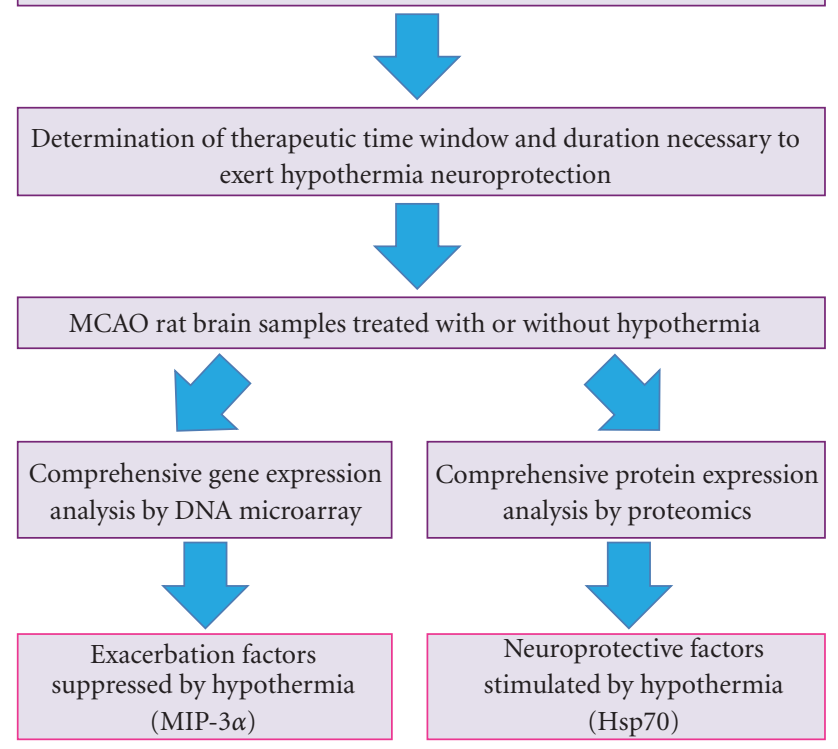

Figure 1: An experimental strategy to identify potential drug targets associated with hypothermia.

of hypothermia required for exerting neuroprotective effects (Figure 1).

\section{Therapeutic Time Window and Duration of Hypothermia}

It is not known precisely when the series of events leading to final cell death and dissolution becomes irreversible. However, there is overwhelming evidence that the early recovery phase, before the start of secondary deterioration, represents the effective window of opportunity for initiation of postinsult cooling [18]. A continuous comparison of stroke damage with or without hypothermia would provide massive amount of information that would be difficult to interpret precisely; therefore, it is necessary to compare appropriate samples according to the therapeutic time window and duration of hypothermia required to exert a neuroprotective effect. Precise control of brain temperature is critical for the evaluation of the efficacy of mild postischemic hypothermia and for the acquisition of reproducible gene and protein expression patterns. To predict the effective phase of hypothermia, we established a rat experimental stroke model: a 2-hr transient intraluminal occlusion of the middle cerebral artery (MCAO), which resulted in severe brain infarct with almost complete striatal and extensive cortical damages, was combined with a multichannel computer-controlled brain temperature control system that enabled us to maintain a constant brain temperature for more than 2 days [19]. Rats were implanted with a telemetry brain temperature probe with its temperature sensor inserted approximately $4 \mathrm{~mm}$ from the skull surface (lower layer of the cerebral cortex). The rats were individually housed in acrylic cages with wooden chips. To induce hypothermia, each cage was placed in a room maintained at $4^{\circ} \mathrm{C}$, and the cortical temperature was continuously and individually monitored from the freely moving rats. Cooling fans attached to the cage lid were turned on when the brain temperature was higher than $35^{\circ} \mathrm{C}$ and were stopped when the brain temperature was below $34^{\circ} \mathrm{C}$. To maintain normothermia, rats were kept under room temperature. Because the brain temperature increased during MCAO, the term "normothermia" does not refer to a certain controlled temperature. For instance, in our rat model, normothemic rat brain temperature increased over $38^{\circ} \mathrm{C}$ for more than $18 \mathrm{hr}$ [19]. Similar brain temperature control systems that used water sprays for cooling instead of cold rooms have been reported [20,21]. The surgical placement of the temperature probes into the brain on the day prior to MCAO should be taken into consideration during further experimentation because the stab wounds might have had a preconditioning effect. The therapeutic time window is considered to depend upon the severity of the insult, depth of damage, and duration of cooling [22-24].

We identified the therapeutic time window of mild hypothermia at $35^{\circ} \mathrm{C}$ in rats subjected to hypothermia after a 2-hr MCAO [19]. The brain infarct volumes measured 2 days after MCAO were $288.6 \pm 21.5 \mathrm{~mm}^{3}$ in normothermic rats. In contrast, postischemic hypothermia significantly reduced the volume when introduced at $0 \mathrm{hr}\left(120.0 \pm 21.7 \mathrm{~mm}^{3}, P<\right.$ $.005), 2 \mathrm{hr}\left(147.0 \pm 26.3 \mathrm{~mm}^{3}, P<.005\right)$, and $4 \mathrm{hr}(209.9 \pm$ $\left.33.5 \mathrm{~mm}^{3}, P<.025\right)$ after normothermic reperfusion. No significant reduction was observed when postischemic hypothermia was introduced $6 \mathrm{hr}$ after reperfusion $(244.3 \pm$ $35.5 \mathrm{~mm}^{3}$ ). The therapeutic time window of hypothermia was therefore concluded as $4 \mathrm{hr}$ after reperfusion in our model. However, even $4 \mathrm{hr}$ of hypothermia when introduced immediately after reperfusion did not significantly reduce brain infarct volumes $\left(182.3 \pm 29.4 \mathrm{~mm}^{3}\right)$ as compared to the volumes in normothermic rats $\left(219.3 \pm 29.9 \mathrm{~mm}^{3}\right)$. The infarct volume after $24 \mathrm{hr}$ of hypothermia $\left(63.1 \pm 28.2 \mathrm{~mm}^{3}\right)$ was significantly smaller than that after normothermia $\left(219.2 \pm 39.7 \mathrm{~mm}^{3}, P<.01\right)$, suggesting that hypothermia should be maintained for longer than $4 \mathrm{hr}$ in our model to obtain neuroprotective effects. This finding is consistent with reports that mention the importance of prolonged hypothermia for persistent neuroprotection $[25,26]$. Hypothermia may exert neuroprotective effects in ischemic brains by regulating particular injurious factors within specific time intervals.

\section{DNA Microarray Analysis}

DNA microarray analysis is a useful tool for determining gene expression [27-29]. A number of endogenous proteins have been reported to be induced during ischemia, including several involved in inflammation and neuronal death such as the MAP kinase protein and heat shock proteins (HSP) that play roles in both tissue damage and reorganization [3035]. Lu et al. [36] reported upregulation of immediate early genes, transcription factors, and HSPs as early as $30 \mathrm{~min}$ after MCAO in $30 \mathrm{~min}$ or $2 \mathrm{hr}$ transient rat MCAO models, and upregulation of genes related to inflammation, apoptosis, the cytoskeleton, and metabolism that peaked within 4-24 hr after MCAO. Figure 2 shows expression patterns of several 


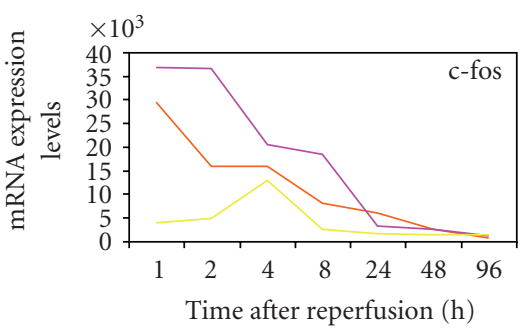

(a)

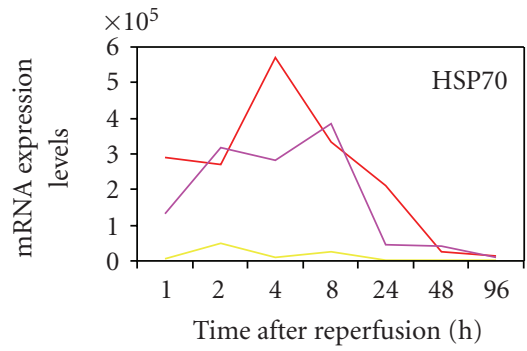

(d)

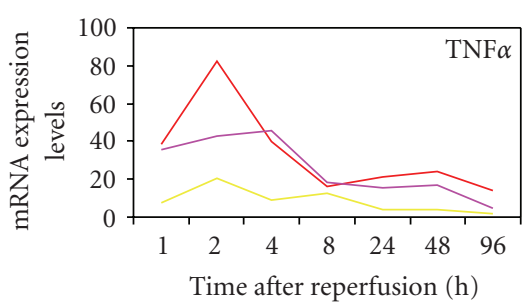

(g)

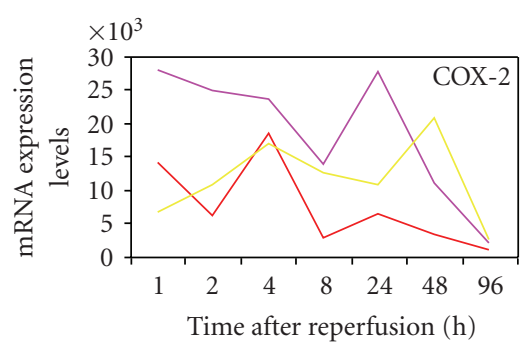

(j)

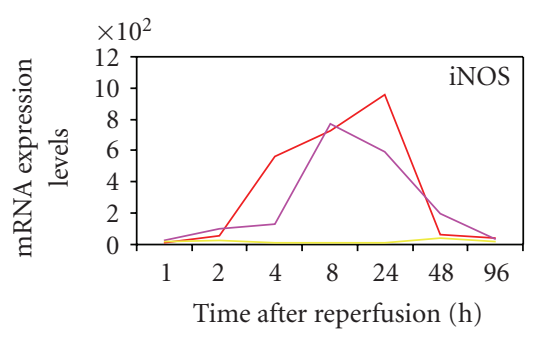

(b)

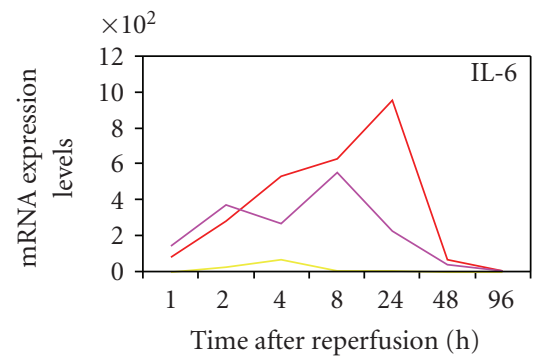

(e)

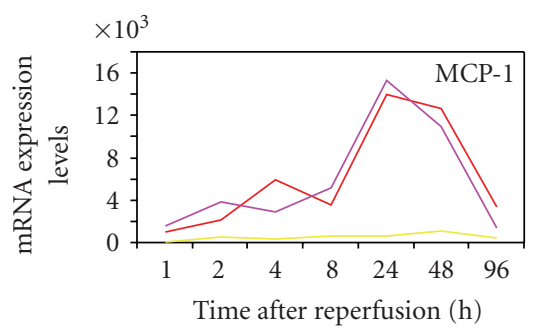

(h)

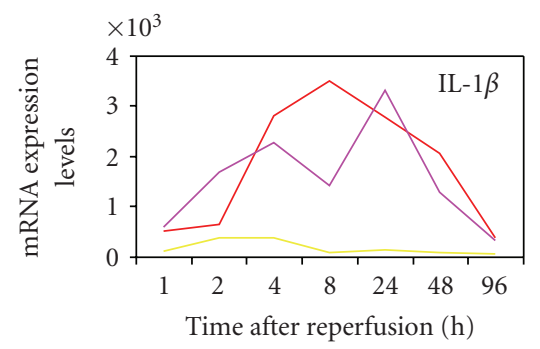

(k)

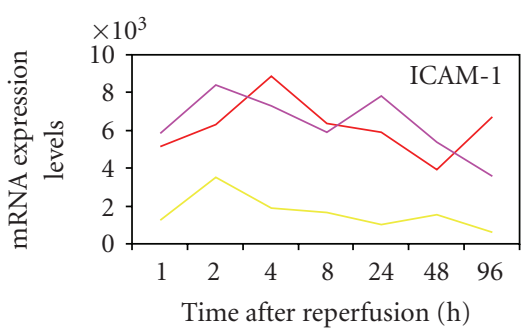

(c)

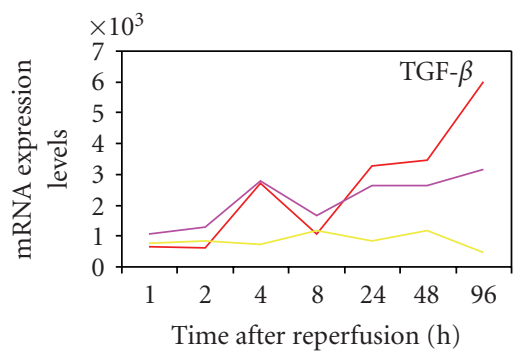

(f)

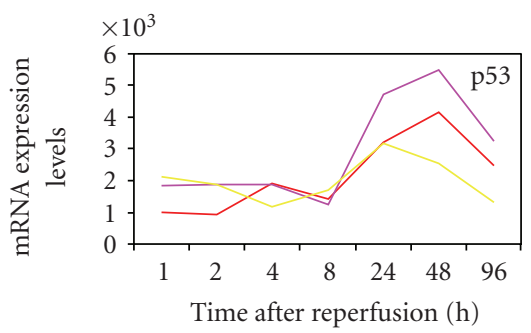

(i)

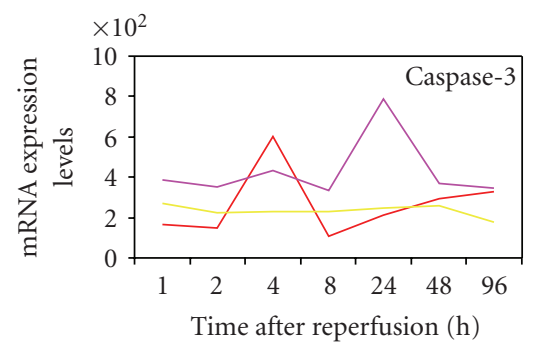

(1)

FIGURE 2: Stress-related genes expression in rat brains after reperfusion under normothermia. The expression levels of each mRNA in ischemic core (red), penumbra (purple), and normal (yellow) regions were quantified by real-time PCR, and their mRNA expression levels were shown as a gene copy number per $1 \mathrm{ng}$ of polyA ${ }^{+}$RNA. The procedure used has been previously described [17].

stress-related genes after reperfusion in ischemic brains of our rat model under normothermia. The expression level of $c$-Fos mRNA reached the peak during MCAO and sustained at least for $1 \mathrm{~h}$ after reperfusion. Hsp70 mRNA expression was also high in the beginning of reperfusion. Interestingly, tumor necrosis factor- $\alpha(T N F-\alpha)$, interleukine$1 \beta(I L-1 \beta)$, inducible nitric oxide synthase (iNOS), and $I L$ 6 mRNAs were transiently and sequentially induced after reperfusion. In contrast, monocyte chemotactic protein1 (MCP-1), transforming growth factor- $\beta$ (TGF- $\beta)$, and p53 mRNAs gradually increased along with progression of the disease. Gene expression analysis provides a large amount of information regarding expression changes of thousands of genes, and time-dependent changes should therefore be analyzed to grasp the entire picture. Hence, the information of therapeutic time window and time duration of hypothermia was exploited. The therapeutic time window of hypothermia in our model was $4 \mathrm{hr}$, so we hypothesized that gene expression changes occurring prior to this time point are important for hypothermic neuroprotection. Of the 8000 transcripts represented on the Affymetrix Rat U34A GeneChip, $45 \pm 8 \%$ showed a present call (a specific signal with statistical significance) in both hypothermia and normothermia brains during the $4 \mathrm{hr}$ reperfusion [19]. Approximately 400 of the genes were upregulated more than 2 -fold, but no genes were reproducibly suppressed. 
Of the upregulated genes, 22 were upregulated more than 20 -fold, including Hsp70 mRNA. Interestingly, most of the genes whose expression was significantly suppressed by hypothermia were inflammatory-related molecules including IL- $1 \beta$ and osteopontin (OPN), suggesting that the suppression of neuroinflammation primarily contributes to neuroprotection. OPN has a proinflammatory role in some diseases [37-40], although the neuroprotective role of OPN is also reported [41]. Further studies are needed to elucidate the roles of OPN in ischemic pathophysiology.

Meanwhile, we also speculated that the interruption of hypothermia is implicated in ischemic damage because the duration necessary to exert hypothermic neuroprotection was longer than $4 \mathrm{hr}$. To identify genes involved in the recovery phase before the secondary deterioration, we compared gene expression in ischemic brains kept in hypothermia for $8 \mathrm{hr}$ during reperfusion with those kept in hypothermia for the first $4 \mathrm{hr}$ followed by $4 \mathrm{hr}$ normothermia. We identified 12 genes functionally related to neuroinflammation, including $c$-Fos, early growth response 1 and 4 (Egr-1, and Egr-4), MAPK phosphatase-1 (MKP-1), macrophage inflammatory protein-3 $\alpha(M I P-3 \alpha), M C P-1$, and $I L-1 \beta$ [19]. Egr-1 is a master switch activated by ischemia to trigger the expression of pivotal regulators of inflammation, such as IL- $1 \beta$, MCP1 , and macrophage inflammatory protein-2 (MIP-2), in addition to coagulation and vascular hyperpermeability [43]. Deng et al. [44] demonstrated that postischemic mild hypothermia decreases inflammatory responses by suppressing intercellular adhesion molecule-1 (ICAM-1), an essential molecule for peripheral leucocyte recruitment into brain parenchyma. Stroke-mediated release of proinflammatory cytokines and adhesion molecules is a relevant component of the complex pathophysiological response [45]. Those inflammatory mediators enable leukocytes to adhere to the vascular endothelial cells and to infiltrate inflammatory cells from the circulation into the ischemic brain within hours after ischemic damage. Studies addressing efficacy of mild hypothermia also indicate the importance of microglia activation $[16,44]$, nuclear-factor kappaB $(\mathrm{NF}-\kappa \mathrm{B})$ activation [46], or nitric oxide production [47].

\section{Proteomic Analysis}

Proteomic analysis is another powerful tool for examining the physiopathologies of diseases. Hence, proteomic studies using brain tissues, blood, or cerebrospinal fluids of stroke patients [48] or experimental models $[42,49]$ have been performed to elucidate the pathogenesis of stroke and to identify novel diagnostic biomarkers. Proteomic profiling generally consists of 2 technologies: two-dimensional polyacrylamide gel electrophoresis (2D-PAGE) for the comparison of protein expression and LCQ-advantage micro-LC/MS/MS system for protein identification. In our experiments, the criteria for altered protein expression between hypothermia and normothermia were set as a ratio of greater than 1.5fold or less than 1/1.5-fold. Out of approximately 1200 spots on 2D-PAGE, 44 were identified with a statistically significant difference in mean values. Thirteen of the 44 spots were upregulated by hypothermia more than 1.5 -fold
(1.50-1.85) compared with normothermia. Among them, a spot identified as Hsp70 was studied further because it was upregulated by MCAO and was further induced by hypothermia, although hypothermia itself did not induce Hsp70 in nonischemic brains [50]. This observation was confirmed by Hsp70-specific enzyme-linked immunosorbent assay (ELISA), western blotting, and immunohistochemistry of ischemic brain tissues. Hsp70 is a chaperone protein that can fold or refold proteins, coordinate protein trafficking, inhibit protein aggregation or degradation, and exhibit antiapoptotic and anti-inflammatory activities under physiological conditions [51-53]. Several reports have suggested that Hsp70 inhibits NF- $\kappa$ B transcription by stabilizing NF$\kappa \mathrm{B}$ and preventing its phosphorylation [54]. Zheng et al. [55] recently demonstrated that the interaction between Hsp70 and the NF- $\kappa \mathrm{B}: \mathrm{I} \kappa \mathrm{B}$ complex significantly inhibits NF- $\kappa \mathrm{B}$ activation and leads to a decrease in NF- $\kappa \mathrm{B}$-regulated genes in MCAO-treated Hsp70 transgenic mice. The expression of Hsp70 and Hsp27 can be induced in glial cells and neurons by a wide range of noxious stimuli including ischemia [56, 57], epileptic seizure [58], and hyperthermia [59]. Neuroprotective effects of Hsp70 against ischemic injury have been reported for drugs that induce Hsp70 expression [60] and in Hsp70 transgenic mice [61]. However, the induction of Hsp70 by hypothermia has not been reported to date. Hsp27 was also induced by ischemia, but was slightly suppressed by hypothermia (Figure 3). GAP43, a constitutive protein in the brain, and other Hsps, including Hsp40, Hsp90, Grp78, Grp94, PDI, and ORP150, were detectable under normal conditions and were not affected by either hypothermia or ischemia (Figure 3 and unpublished data). Hence, Hsp70 accumulation by hypothermia was unique. Recently Hagiwara et al. [62] reported that hypothermia at $34^{\circ} \mathrm{C}$ increased the Hsp70 expression level in lipopolysaccharide (LPS)-stimulated RAW264.7 cells, although IL-1 $\beta$, IL- 6 and TNF- $\alpha$ expression levels were reduced under the same conditions. In contrast to the protein level of Hsp70, Hsp70 mRNA expression in our model was suppressed by hypothermia. Rubtsova et al. [63] reported that the $5^{\prime}$ untranslated region of human $H s p 70$ mRNA represents an internal ribosome entry site (IRES) with relative activity similar to that of the classical picornaviral IRESs, implying posttranscriptional regulation of Hsp70. While it is unknown whether there is a similar IRES element in rat Hsp70 mRNA and if the IRES is activated under hypothermia, this finding merits further investigation because it hints at the identity of neuroprotectants that increase Hsp70 by a novel mechanism. The neuroprotective roles of Hsp70 in hypothermia are also worthy of further investigation.

\section{Novel Targets for Therapeutic Drugs Acting as "Hypothermia-Like Neuroprotectants"}

Neuroinflammation is involved in the pathogenesis of many CNS diseases. In stroke, excess inflammatory activation results in brain injury and ultimately causes severe neuronal apoptosis [64]. Anti-inflammatory therapies using immunosuppressants [65] or biogenetics such as an antiICAM-1-neutralizing antibody [66] have been applied in 


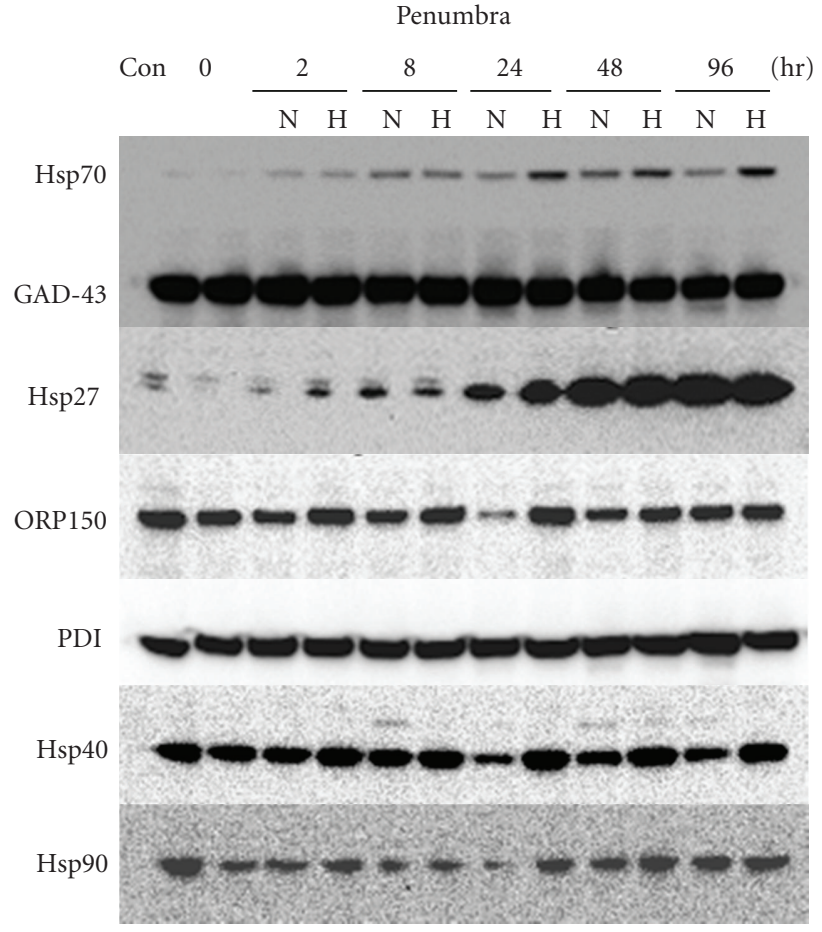

(a)

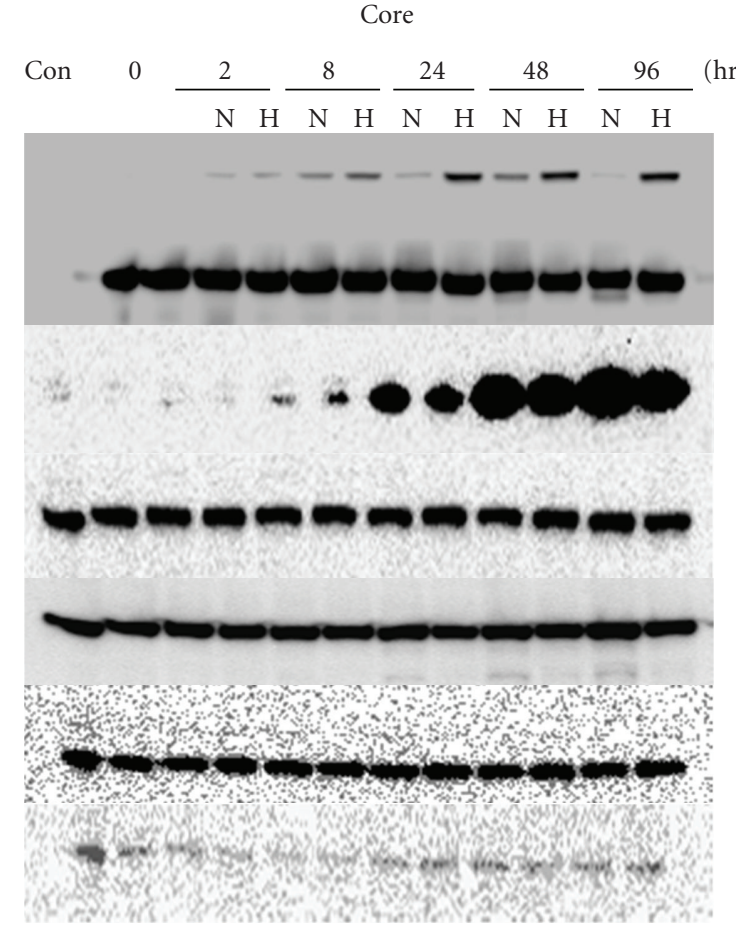

(b)

FIGURE 3: Effect of occlusion of the middle cerebral artery (MCAO) and hypothermia on chaperones expression in rat brains. Western blot analysis for Hsp70, Hsp27, Hsp40, Hsp90, ORP150, PDI, and GAD-43 was performed using protein samples from the penumbra and core regions of rat ischemic brains at the indicated time points after reperfusion. GAD43 protein served as an internal control. N: normothermia, H: hypothermia. "Con" denotes protein samples from normal rat brains. The procedure used has been previously described [42].

both preclinical and clinical contexts. MCP-1 is also considered a promising drug target due to its possible role in exacerbating ischemic injury, controlling blood-brain barrier permeability, and driving leukocyte infiltration into the brain parenchyma in stroke $[67,68]$. Our DNA microarray analysis revealed that both cerebral $M I P-3 \alpha$ and CC-chemokine receptor 6 (CCR6) genes were significantly induced in the core and penumbra regions of MCAO rat brains, and hypothermia suppressed expression of both genes [69]. The MIP-3 $\alpha$ chemokine is expressed in macrophages, dendritic cells, and lymphocytes. Depending on the conditions, MIP$3 \alpha$ acts both constitutively and inducibly and serves as a chemoattractant, especially in epithelial immunological systems such as those of the skin and mucosa $[70,71]$. In CNS, MIP-3 $\alpha$ expression has been reported in autoimmune encephalomyelitis [72] and stroke [36, 73], but its full role has not yet been determined. CCR6, the only receptor for MIP-3 $\alpha$, is expressed in multiple leukocyte subsets, and is implicated in diverse inflammatory responses in animal models, such as allergic airway disorders, inflammatory bowel disease, and autoimmune encephalitis [74, 75]. Strikingly, intracerebral administration of an an anti-MIP- $3 \alpha-$ neutralizing antibody significantly reduced infarct volumes in MCAO rats $\left(187.5 \pm 37.0 \mathrm{~mm}^{3}\right)$ compared with those of vehicle $\left(304.0 \pm 32.8 \mathrm{~mm}^{3}\right)$ and of control mouse IgG $\left(291.3 \pm 33.5 \mathrm{~mm}^{3}\right)$, suggesting that MIP-3 $\alpha$-CCR6 signaling is dominant in neuroinflammatory cascades involved in brain ischemia. Interestingly, MIP- $3 \alpha$ administration into the striatum dose-dependently induced CCR6, but not CCR1 or $C C R 2$, gene expression. Intrastriatal injection of IL- $1 \beta$ and TNF- $\alpha$ upregulated MIP-3 $\alpha$ and CCR6 mRNA expression levels in a sequential fashion. Robust induction of IL- $1 \beta$ and TNF- $\alpha$ was observed at an acute phase of MCAO prior to MIP-3 $\alpha$ expression, suggesting that these cytokines may be directly involved in MIP- $3 \alpha$ production.

$M I P-3 \alpha$ mRNA expression was markedly induced by IL- $1 \beta$ and TNF- $\alpha$ in rat astrocytes but not in microglia or neurons. Astrocytes are reported to emerge around the damaged area after ischemic injury [76] and to produce MIP$3 \alpha$ in a mouse experimental autoimmune encephalomyelitis model [77]. In contrast, rat primary microglia constitutively expresses the CCR6 gene in normal culture conditions while astrocytes or neurons do not. Strikingly, the expression of both iNOS and IL- $1 \beta$ were induced in MIP- $3 \alpha$-treated microglia. Microglia are activated and accumulate around the injured area following ischemia [78]. Because hypothermia reportedly inhibits $\mathrm{NF}-\kappa \mathrm{B}$ directly by decreasing $\mathrm{I} \kappa \mathrm{B}$ kinase activity in MCAO rat brains [15], one of the suppressive effects of hypothermia on MIP- $3 \alpha$ induction may be a direct inhibition of NF- $\kappa \mathrm{B}$ activity in astrocytes. Another possibility is that the upregulation of Hsp70 expression by hypothermia inhibits MIP- $3 \alpha$ expression by the interaction 


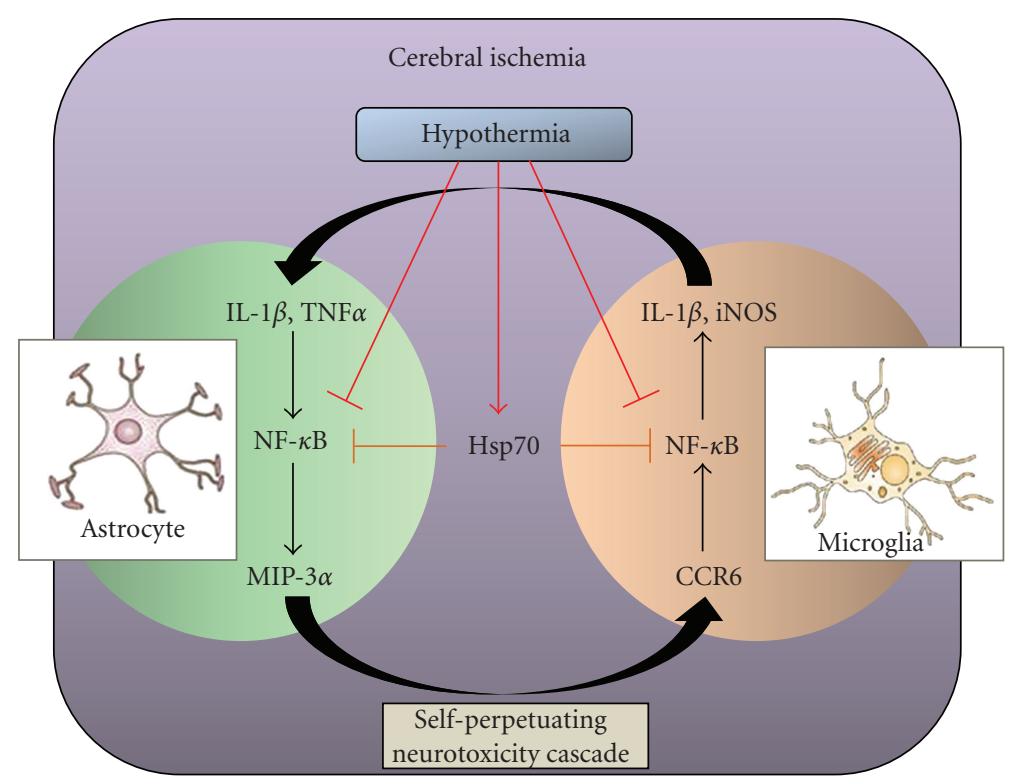

FIGURE 4: A putative neuroinflammatory cascade exacerbated by MIP-3 $\alpha$-CCR6 signaling and protected by Hsp70 in ischemic rat brains. In ischemic brains, the activation of neuroinflammatory cascades including MIP-3 $\alpha$-CCR6 signaling is speculated to progress as follows: astrocytes activated by proinflammatory cytokines like IL- $1 \beta$ and TNF $\alpha$ stimulate MIP- $3 \alpha$ release. MIP-3 $\alpha$ activates microglia through CCR6 and the cells produce other stress-related proteins like iNOS and IL- $1 \beta$. Production of IL- $1 \beta$ further accelerates astrocyte activation. The selfperpetuating neurotoxicity cascade may damage surrounding neurons and brain tissues. On the other hand, hypothermia suppresses the cytokines and chemokines production in part by direct inhibition of NF-kB transcription via decreased IkB kinase activity. Our experiment has also elucidated the potential effect of hypothermia, which stimulated Hsp70 production in MCAO brains. Accumulated Hsp70 may inhibit NF-kB transcription by directly interacting with the NF-kB:IkB complex in astrocytes and microglia.

of Hsp70 with the $5^{\prime}$-untranslated regulatory region of MIP$3 \alpha$ mRNA that contains NF- $\kappa$ B binding sites, as described by Zheng et al. [55]. The activation of astrocytes and microglia may accelerate brain injury-induced neuroinflammation via MIP-3 $\alpha$-CCR6 signaling, whereas hypothermia would suppress this signaling via Hsp70-dependent and independent pathways (Figure 4).

The physiological roles of MIP- $3 \alpha$-CCR6 signaling in the CNS have yet to be fully determined, because various roles of chemokines have recently been proposed in brain, including as neurotransmitters and neuromodulators [79, 80]. The interactions between MIP-3 $\alpha$-CCR6 signaling and other pathways involved in the ischemic pathology, such as excitotoxicity, acidotoxicity, oxidative stress, and apoptosis, also should be addressed. For instance, oxidative stress is considered one of the primary risk factors that exacerbate the damage by cerebral ischemia, and several components of ROS are generated after ischemia/reperfusion injury [81]. Kil et al. [82] have reported that ROS production by leukocytes and microglia in the ischemia brain is strongly suppressed by hypothermia. Apoptosis is another important cause because of the significant contribution to the cell death subsequent to ischemia/reperfusion injury [83]. Jong et al. [84] have reported the reduction in levels of matrix metalloproteinases (MMPs) and increased expression of tissue inhibitor of metalloproteinase (TIMP)-2 in response to mild hypothermia therapy in experimental stroke. Precise evaluation of ROS, MMPs, and TIMPs in MCAO rat brains treated with an anti-MIP-3 $\alpha$-neutralizing antibody may provide insights into these interactions.

\section{Conclusions}

This paper described the utilization of current technologies such as DNA microarray and proteomics to reveal the specific mechanisms and key molecules involved in the neuroprotective effects of hypothermia against ischemic injury. The therapeutic time window and duration of hypothermia necessary to exert neuroprotective effects were determined using a brain temperature control system. Comprehensive gene expression analysis showed that suppression of neuroinflammatory cascades including MIP-3 $\alpha$-CCR6 signaling may primarily contribute to the neuroprotective effects of hypothermia. In contrast, proteomics identified Hsp70 as a potential effector. Although the physiological roles and potential cross-talk between these molecules remain to be elucidated, these approaches may be promising for the discovery of antistroke pharmaceutical drug targets.

\section{Acknowledgments}

Authors express their deep gratitude to Drs. Shigeru Ohkawa, Hiroyuki Odaka, Hideaki Nagaya, and Keisuke Hirai of the Pharmaceutical Research Division, Takeda Pharmaceutical Company, Ltd., for their stimulating interests and continuing encouragement during the course of this work. 


\section{References}

[1] G. A. Donnan, M. Fisher, M. Macleod, and S. M. Davis, "Stroke," The Lancet, vol. 371, no. 9624, pp. 1612-1623, 2008.

[2] C. P. Warlow, "Epidemiology of stroke," The Lancet, vol. 352, no. 3, pp. 1-4, 1998.

[3] V. L. Feigin, C. M. M. Lawes, D. A. Bennett, and C. S. Anderson, "Stroke epidemiology: a review of populationbased studies of incidence, prevalence, and case-fatality in the late 20th century," Lancet Neurology, vol. 2, no. 1, pp. 43-53, 2003.

[4] C. S. Kidwell, D. S. Liebeskind, S. Starkman, and J. L. Saver, "Trends in acute ischemic stroke trials through the 20th century," Stroke, vol. 32, no. 6, pp. 1349-1359, 2001.

[5] A. R. Green, T. Odergren, and T. Ashwood, "Animal models of stroke: do they have value for discovering neuroprotective agents?" Trends in Pharmacological Sciences, vol. 24, no. 8, pp. 402-408, 2003.

[6] H. Yoshida, H. Yanai, Y. Namiki, K. Fukatsu-Sasaki, N. Furutani, and N. Tada, "Neuroprotective effects of edaravone: a novel free radical scavenger in cerebrovascular injury," CNS Drug Reviews, vol. 12, no. 1, pp. 9-20, 2006.

[7] M. A. Yenari, J. E. Lee, and R. G. Giffard, "Stress proteins and ischemic tolerance," in Cerebral Ischemic Tolerence, B. Schaller, Ed., pp. 103-121, Nova Science Publishers, Huntington, NY, USA, 2004.

[8] Z. Zheng, J. E. Lee, and M. A. Yenari, "Stroke: molecular mechanisms and potential targets for treatment," Current Molecular Medicine, vol. 3, no. 4, pp. 361-372, 2003.

[9] T. Miyazawa, A. Tamura, S. Fukui, and K.-A. Hossmann, "Effect of mild hypothermia on focal cerebral ischemia. Review of experimental studies," Neurological Research, vol. 25, no. 5, pp. 457-464, 2003.

[10] H. Yanamoto, I. Nagata, Y. Niitsu et al., "Prolonged mild hypothermia therapy protects the brain against permanent focal ischemia," Stroke, vol. 32, no. 1, pp. 232-239, 2001.

[11] N. Kawai, M. Okauchi, K. Morisaki, and S. Nagao, "Effects of delayed intraischemic and postischemic hypothermia on a focal model of transient cerebral ischemia in rats," Stroke, vol. 31, no. 8, pp. 1982-1989, 2000.

[12] M. Holzer, F. Sterz, J. M. Darby et al., "Mild therapeutic hypothermia to improve the neurologic outcome after cardiac arrest," The New England Journal of Medicine, vol. 346, no. 8, pp. 549-556, 2002.

[13] S. A. Bernard, T. W. Gray, M. D. Buist et al., "Treatment of comatose survivors of out-of-hospital cardiac arrest with induced hypothermia," The New England Journal of Medicine, vol. 346, no. 8, pp. 557-563, 2002.

[14] H. Y. Kil, J. Zhang, and C. A. Piantadosi, "Brain temperature alters hydroxyl radical production during cerebral ischemia/reperfusion in rats," Journal of Cerebral Blood Flow and Metabolism, vol. 16, no. 1, pp. 100-106, 1996.

[15] H. S. Han, M. Karabiyikoglu, S. Kelly, R. A. Sobel, and M. A. Yenari, "Mild hypothermia inhibits nuclear factor$\kappa \mathrm{B}$ translocation in experimental stroke," Journal of Cerebral Blood Flow and Metabolism, vol. 23, no. 5, pp. 589-598, 2003.

[16] G. J. Wang, H. Y. Deng, C. M. Maier, G. H. Sun, and M. A. Yenari, "Mild hypothermia reduces ICAM-1 expression, neutrophil infiltration and microglia/monocyte accumulation following experimental stroke," Neuroscience, vol. 114, no. 4, pp. 1081-1090, 2002.

[17] M. A. Yenari, S. Iwayama, D. Cheng et al., "Mild hypothermia attenuates cytochrome $\mathrm{c}$ release but does not alter Bcl-2 expression or caspase activation after experimental stroke," Journal of Cerebral Blood Flow and Metabolism, vol. 22, no. 1, pp. 29-38, 2002.

[18] P. P. Drury, L. Bennet, and A. J. Gunn, "Mechanisms of hypothermic neuroprotection," Seminars in Fetal and Neonatal Medicine, vol. 15, no. 5, pp. 287-292, 2010.

[19] H. Ohta, Y. Terao, Y. Shintani, and Y. Kiyota, "Therapeutic time window of post-ischemic mild hypothermia and the gene expression associated with the neuroprotection in rat focal cerebral ischemia," Neuroscience Research, vol. 57, no. 3, pp. 424-433, 2007.

[20] F. Colbourne, G. R. Sutherland, and R. N. Auer, "An automated system for regulating brain temperature in awake and freely moving rodents," Journal of Neuroscience Methods, vol. 67, no. 2, pp. 185-190, 1996.

[21] S. DeBow and F. Colbourne, "Brain temperature measurement and regulation in awake and freely moving rodents," Methods, vol. 30 , no. 2 , pp. 167-171, 2003.

[22] F. Colbourne, G. Sutherland, and D. Corbett, "Postischemic hypothermia: a critical appraisal with implications for clinical treatment," Molecular Neurobiology, vol. 14, no. 3, pp. 171201, 1997.

[23] G. Z. Markarian, J. H. Lee, D. J. Stein, and S.-C. Hong, "Mild hypothermia: therapeutic window after experimental cerebral ischemia," Neurosurgery, vol. 38, no. 3, pp. 542-551, 1996.

[24] C. M. Maier, K. V. B. Ahern, M. L. Cheng, J. E. Lee, M. A. Yenari, and G. K. Steinberg, "Optimal depth and duration of mild hypothermia in a focal model of transient cerebral ischemia: effects on neurologic outcome, infarct size, apoptosis, and inflammation," Stroke, vol. 29, no. 10, pp. 2171-2180, 1998.

[25] F. Colbourne, D. Corbett, Z. Zhao, J. Yang, and A. M. Buchan, "Prolonged but delayed postischemic hypothermia: a longterm outcome study in the rat middle cerebral artery occlusion model," Journal of Cerebral Blood Flow and Metabolism, vol. 20, no. 12, pp. 1702-1708, 2000.

[26] D. Corbett, M. Hamilton, and F. Colbourne, "Persistent neuroprotection with prolonged postischemic hypothermia in adult rats subjected to transient middle cerebral artery occlusion," Experimental Neurology, vol. 163, no. 1, pp. 200206, 2000.

[27] A. Schulze and J. Downward, "Navigating gene expression using microarrays - a technology review," Nature Cell Biology, vol. 3, no. 8, pp. E190-E195, 2001.

[28] J. C. Mills, K. A. Roth, R. L. Cagan, and J. I. Gordon, "DNA microarrays and beyond: completing the journey from tissue to cell," Nature Cell Biology, vol. 3, no. 8, pp. E175-E178, 2001.

[29] K. Mirnics, F. A. Middleton, D. A. Lewis, and P. Levitt, "Analysis of complex brain disorders with gene expression microarrays: schizophrenia as a disease of the synapse," Trends in Neurosciences, vol. 24, no. 8, pp. 479-486, 2001.

[30] P. T. Akins, P. K. Liu, and C. Y. Hsu, "Immediate early gene expression in response to cerebral ischemia: friend or foe?" Stroke, vol. 27, no. 9, pp. 1682-1687, 1996.

[31] J. Koistinaho and T. Hökfelt, "Altered gene expression in brain ischemia," NeuroReport, vol. 8, no. 2, pp. R1-R8, 1997.

[32] F. R. Sharp, A. Lu, Y. Tang, and D. E. Millhorn, "Multiple molecular penumbras after focal cerebral ischemia," Journal of Cerebral Blood Flow and Metabolism, vol. 20, no. 7, pp. 10111032, 2000.

[33] S. J. Read, A. A. Parsons, D. C. Harrison et al., "Stroke genomics: approaches to identify, validate, and understand ischemic stroke gene expression," Journal of Cerebral Blood Flow and Metabolism, vol. 21, no. 7, pp. 755-778, 2001. 
[34] A. Lu, Y. Tang, R. Ran, J. F. Clark, B. J. Aronow, and F. R. Sharp, "Genomics of the periinfarction cortex after focal cerebral ischemia," Journal of Cerebral Blood Flow and Metabolism, vol. 23, no. 7, pp. 786-810, 2003.

[35] N. Kawahara, Y. Wang, A. Mukasa et al., "Genome-wide gene expression analysis for induced ischemic tolerance and delayed neuronal death following transient global ischemia in rats," Journal of Cerebral Blood Flow and Metabolism, vol. 24, no. 2, pp. 212-223, 2004.

[36] X.-C. M. Lu, A. J. Williams, C. Yao et al., "Microarray analysis of acute and delayed gene expression profile in rats after focal ischemic brain injury and reperfusion," Journal of Neuroscience Research, vol. 77, no. 6, pp. 843-857, 2004.

[37] D. T. Denhardt, M. Noda, A. W. O’Regan, D. Pavlin, and J. S. Berman, "Osteopontin as a means to cope with environmental insults: regulation of inflammation, tissue remodeling, and cell survival," The Journal of Clinical Investigation, vol. 107, no. 9, pp. 1055-1061, 2001.

[38] X. Wang, C. Louden, T.-L. Yue et al., "Delayed expression of osteopontin after focal stroke in the rat," Journal of Neuroscience, vol. 18, no. 6, pp. 2075-2083, 1998.

[39] J. A. Ellison, F. C. Barone, and G. Z. Feuerstein, "Matrix remodeling after stroke. De novo expression of matrix proteins and integrin receptors," Annals of the New York Academy of Sciences, vol. 890, pp. 204-222, 1999.

[40] J. A. Ellison, J. J. Velier, P. Spera et al., "Osteopontin and its integrin receptor $\alpha(\mathrm{v}) \beta 3$ are upregulated during formation of the glial scar after focal stroke," Stroke, vol. 29, no. 8, pp. 16981707, 1998.

[41] R. Meller, S. L. Stevens, M. Minami et al., "Neuroprotection by osteopontin in stroke," Journal of Cerebral Blood Flow and Metabolism, vol. 25, no. 2, pp. 217-225, 2005.

[42] A. Chen, W. P. Liao, Q. Lu, W. S.F. Wong, and P. T.-H. Wong, "Upregulation of dihydropyrimidinase-related protein 2, spectrin $\alpha$ II chain, heat shock cognate protein 70 pseudogene 1 and tropomodulin 2 after focal cerebral ischemia in rats-A proteomics approach," Neurochemistry International, vol. 50, no. 7-8, pp. 1078-1086, 2007.

[43] S.-F. Yan, T. Fujita, J. Lu et al., "Egr-1, a master switch coordinating upregulation of divergent gene families underlying ischemic stress," Nature Medicine, vol. 6, no. 12, pp. 13551361, 2000.

[44] H. Deng, H. S. Han, D. Cheng, G. H. Sun, and M. A. Yenari, "Mild hypothermia inhibits inflammation after experimental stroke and brain inflammation," Stroke, vol. 34, no. 10, pp. 2495-2501, 2003.

[45] J. Szaflarski, D. Burtrum, F. S. Silverstein, and S. Finkelstein, "Cerebral hypoxia-ischemia stimulates cytokine gene expression in perinatal rats," Stroke, vol. 26, no. 6, pp. 1093-1100, 1995.

[46] M. A. Yenari and H. S. Han, "Influence of hypothermia on post-ischemic inflammation: role of nuclear factor kappa B (NFkB)," Neurochemistry International, vol. 49, no. 2, pp. 164169, 2006.

[47] M. Karabiyikoglu, H. S. Han, M. A. Yenari, and G. K. Steinberg, "Attenuation of nitric oxide synthase isoform expression by mild hypothermia after focal cerebral ischemia: variations depending on timing of cooling," Journal of Neurosurgery, vol. 98, no. 6, pp. 1271-1276, 2003.

[48] C. G. Zimmermann-Ivol, P. R. Burkhard, J. Le Floch-Rohr, L. Allard, D. F. Hochstrasser, and J.-C. Sanchez, "Fatty acid binding protein as a serum marker for the early diagnosis of stroke: a pilot study," Molecular and Cellular Proteomics, vol. 3, no. 1, pp. 66-72, 2004.
[49] L. Sironi, U. Guerrini, E. Tremoli et al., "Analysis of pathological events at the onset of brain damage in stroke-prone rats: a proteomics and magnetic resonance imaging approach," Journal of Neuroscience Research, vol. 78, no. 1, pp. 115-122, 2004.

[50] Y. Terao, S. Miyamoto, K. Hirai et al., "Hypothermia enhances heat-shock protein 70 production in ischemic brains," $\mathrm{Neu}$ roReport, vol. 20, no. 8, pp. 745-749, 2009.

[51] C. Garrido, S. Gurbuxani, L. Ravagnan, and G. Kroemer, "Heat shock proteins: endogenous modulators of apoptotic cell death," Biochemical and Biophysical Research Communications, vol. 286, no. 3, pp. 433-442, 2001.

[52] R. G. Giffard, L. Xu, H. Zhao et al., "Chaperones, protein aggregation, and brain protection from hypoxic/ischemic injury," Journal of Experimental Biology, vol. 207, no. 18, pp. 3213-3220, 2004.

[53] M. A. Yenari, J. Liu, Z. Zheng, Z. S. Vexler, J. E. Lee, and R. G. Giffard, "Antiapoptotic and anti-inflammatory mechanisms of heat-shock protein protection," Annals of the New York Academy of Sciences, vol. 1053, pp. 74-83, 2005.

[54] M. T. Schell, A. L. Spitzer, J. A. Johnson, D. Lee, and H. W. Harris, "Heat shock inhibits NF-kB activation in a doseand time-dependent manner," Journal of Surgical Research, vol. 129, no. 1, pp. 90-93, 2005.

[55] Z. Zheng, J. Y. Kim, H. Ma, J. E. Lee, and M. A. Yenari, "Anti-inflammatory effects of the $70 \mathrm{kDa}$ heat shock protein in experimental stroke," Journal of Cerebral Blood Flow and Metabolism, vol. 28, no. 1, pp. 53-63, 2008.

[56] K. Vass, W. J. Welch, and T. S. Nowak Jr., "Localization of 70$\mathrm{kDa}$ stress protein induction in gerbil brain after ischemia," Acta Neuropathologica, vol. 77, no. 2, pp. 128-135, 1988.

[57] R. W. Currie, J. A. Ellison, R. F. White, G. Z. Feuerstein, X. Wang, and F. C. Barone, "Benign focal ischemic preconditioning induces neuronal Hsp70 and prolonged astrogliosis with expression of Hsp27," Brain Research, vol. 863, no. 1-2, pp. 169-181, 2000.

[58] K. Kato, R. Katoh-Semba, I. K. Takeuchi, H. Ito, and K. Kamei, "Responses of heat shock proteins hsp27, $\alpha \mathrm{B}$-crystallin, and hsp70 in rat brain after kainic acid-induced seizure activity," Journal of Neurochemistry, vol. 73, no. 1, pp. 229-236, 1999.

[59] T. S. Nowak Jr., U. Bond, and M. J. Schlesinger, "Heat shock RNA levels in brain and other tissues after hyperthermia and transient ischemia," Journal of Neurochemistry, vol. 54, no. 2, pp. 451-458, 1990.

[60] M. Ren, Y. Leng, M. Jeong, P. R. Leeds, and D.-M. Chuang, "Valproic acid reduces brain damage induced by transient focal cerebral ischemia in rats: potential roles of histone deacetylase inhibition and heat shock protein induction," Journal of Neurochemistry, vol. 89, no. 6, pp. 1358-1367, 2004.

[61] Y. Matsumori, F. J. Northington, S. M. Hong et al., "Reduction of caspase- 8 and -9 cleavage is associated with increased c-FLIP and increased binding of Apaf- 1 and Hsp70 after neonatal hypoxic/ischemic injury in mice overexpressing Hsp70," Stroke, vol. 37, no. 2, pp. 507-512, 2006.

[62] S. Hagiwara, H. Iwasaka, S. Matsumoto, and T. Noguchi, "Changes in cell culture temperature alter release of inflammatory mediators in murine macrophagic RAW264.7 cells," Inflammation Research, vol. 56, no. 7, pp. 297-303, 2007.

[63] M. P. Rubtsova, D. V. Sizova, S. E. Dmitriev, D. S. Ivanov, V. S. Prassolov, and I. N. Shatsky, "Distinctive properties of the 5'untranslated region of human Hsp70 mRNA," The Journal of Biological Chemistry, vol. 278, no. 25, pp. 22350-22356, 2003. 
[64] Z. Zheng and M. A. Yenari, "Post-ischemic inflammation: molecular mechanisms and therapeutic implications," Neurological Research, vol. 26, no. 8, pp. 884-892, 2004.

[65] Y. Furuichi, T. Noto, J.-Y. Li et al., "Multiple modes of action of tacrolimus (FK506) for neuroprotective action on ischemic damage after transient focal cerebral ischemia in rats," Brain Research, vol. 1014, no. 1-2, pp. 120-130, 2004.

[66] Y. Matsuo, H. Onodera, Y. Shiga et al., "Role of cell adhesion molecules in brain injury after transient middle cerebral artery occlusion in the rat," Brain Research, vol. 656, no. 2, pp. 344352, 1994.

[67] O. B. Dimitrijevic, S. M. Stamatovic, R. F. Keep, and A. V. Andjelkovic, "Effects of the chemokine CCL2 on blood-brain barrier permeability during ischemia-reperfusion injury," Journal of Cerebral Blood Flow and Metabolism, vol. 26, no. 6, pp. 797-810, 2006.

[68] O. B. Dimitrijevic, S. M. Stamatovic, R. F. Keep, and A. V. Andjelkovic, "Absence of the chemokine receptor CCR2 protects against cerebral ischemia/reperfusion injury in mice," Stroke, vol. 38, no. 4, pp. 1345-1353, 2007.

[69] Y. Terao, H. Ohta, A. Oda, Y. Nakagaito, Y. Kiyota, and Y. Shintani, "Macrophage inflammatory protein-3alpha plays a key role in the inflammatory cascade in rat focal cerebral ischemia," Neuroscience Research, vol. 64, no. 1, pp. 75-82, 2009.

[70] A.-S. Charbonnier, N. Kohrgruber, E. Kriehuber, G. Stingl, A. Rot, and D. Maurer, "Macrophage inflammatory protein $3 \alpha$ is involved in the constitutive trafficking of epidermal langerhans cells," Journal of Experimental Medicine, vol. 190, no. 12, pp. 1755-1767, 1999.

[71] D. N. Cook, D. M. Prosser, R. Forster et al., "CCR6 mediates dendritic cell localization, lymphocyte homeostasis, and immune responses in mucosal tissue," Immunity, vol. 12, no. 5, pp. 495-503, 2000.

[72] B. Serafini, S. Columba-Cabezas, F. Di Rosa, and F. Aloisi, "Intracerebral recruitment and maturation of dendritic cells in the onset and progression of experimental autoimmune encephalomyelitis," American Journal of Pathology, vol. 157, no. 6, pp. 1991-2002, 2000.

[73] U. Utans-Schneitz, H. Lorez, W. E.F. Klinkert, J. Da Silva, and W. Lesslauer, "A novel rat CC chemokine, identified by targeted differential display, is upregulated in brain inflammation," Journal of Neuroimmunology, vol. 92, no. 1-2, pp. 179190, 1998.

[74] J. M. Pérez-Cañadillas, A. Zaballos, J. Gutiérrez et al., "NMR solution structure of murine CCL20/MIP-3 $\alpha$, a chemokine that specifically chemoattracts immature dendritic cells and lymphocytes through Its highly specific interaction with the $\beta$-chemokine receptor CCR6," The Journal of Biological Chemistry, vol. 276, no. 30, pp. 28372-28379, 2001.

[75] E. Schutyser, S. Struyf, and J. Van Damme, "The CC chemokine CCL20 and its receptor CCR6," Cytokine and Growth Factor Reviews, vol. 14, no. 5, pp. 409-426, 2003.

[76] M. Zoli, R. Grimaldi, R. Ferrari, I. Zini, and L. F. Agnati, "Short- and long-term changes in striatal neurons and astroglia after transient forebrain ischemia in rats," Stroke, vol. 28, no. 5, pp. 1049-1059, 1997.

[77] E. Ambrosini, S. Columba-Cabezas, B. Serafini, A. Muscella, and F. Aloisi, "Astrocytes are the major intracerebral source of macrophage inflammatory protein-3 $\alpha$ /CCL2 0 in relapsing experimental autoimmune encephalomyelitis and in vitro," GLIA, vol. 41, no. 3, pp. 290-300, 2003.
[78] P. L. Wood, "Microglia as a unique cellular target in the treatment of stroke: potential neurotoxic mediators produced by activated microglia," Neurological Research, vol. 17, no. 4, pp. 242-248, 1995.

[79] A. H. De Haas, H. R. J. Van Weering, E. K. De Jong, H. W. G. M. Boddeke, and K. P. H. Biber, "Neuronal chemokines: versatile messengers in central nervous system cell interaction," Molecular Neurobiology, vol. 36, no. 2, pp. 137-151, 2007.

[80] W. Rostène, P. Kitabgi, and S. M. Parsadaniantz, "Chemokines: a new class of neuromodulator?" Nature Reviews Neuroscience, vol. 8, no. 11, pp. 895-904, 2007.

[81] P. H. Chan, "Reactive oxygen radicals in signaling and damage in the ischemic brain," Journal of Cerebral Blood Flow and Metabolism, vol. 21, no. 1, pp. 2-14, 2001.

[82] H. Y. Kil, J. Zhang, and C. A. Piantadosi, "Brain temperature alters hydroxyl radical production during cerebral ischemia/reperfusion in rats," Journal of Cerebral Blood Flow and Metabolism, vol. 16, no. 1, pp. 100-106, 1996.

[83] L. Liu, J. Y. Kim, M. A. Koike et al., "FasL shedding is reduced by hypothermia in experimental stroke," Journal of Neurochemistry, vol. 106, no. 2, pp. 541-550, 2008.

[84] E. L. Jong, J. Y. Yone, M. E. Moseley, and M. A. Yenari, "Reduction in levels of matrix metalloproteinases and increased expression of tissue inhibitor of metalloproteinase2 in response to mild hypothermia therapy in experimental stroke," Journal of Neurosurgery, vol. 103, no. 2, pp. 289-297, 2005. 


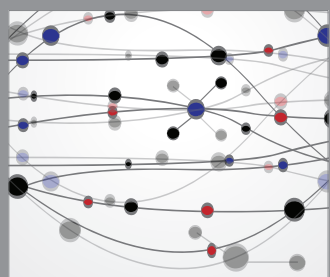

The Scientific World Journal
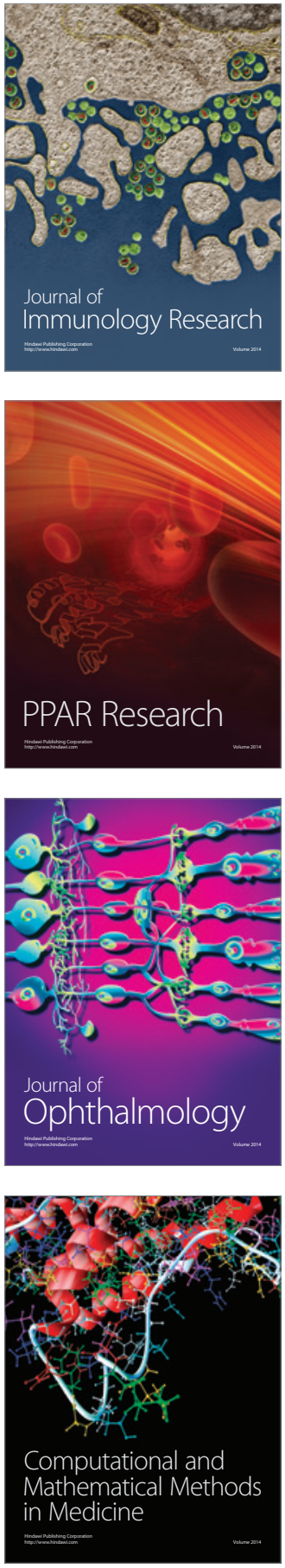

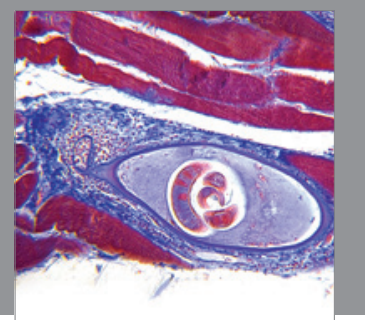

Gastroenterology

Research and Practice
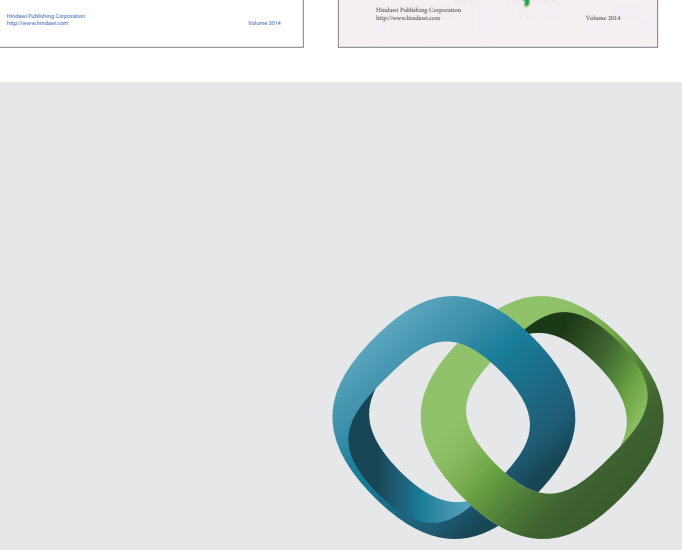

\section{Hindawi}

Submit your manuscripts at

http://www.hindawi.com
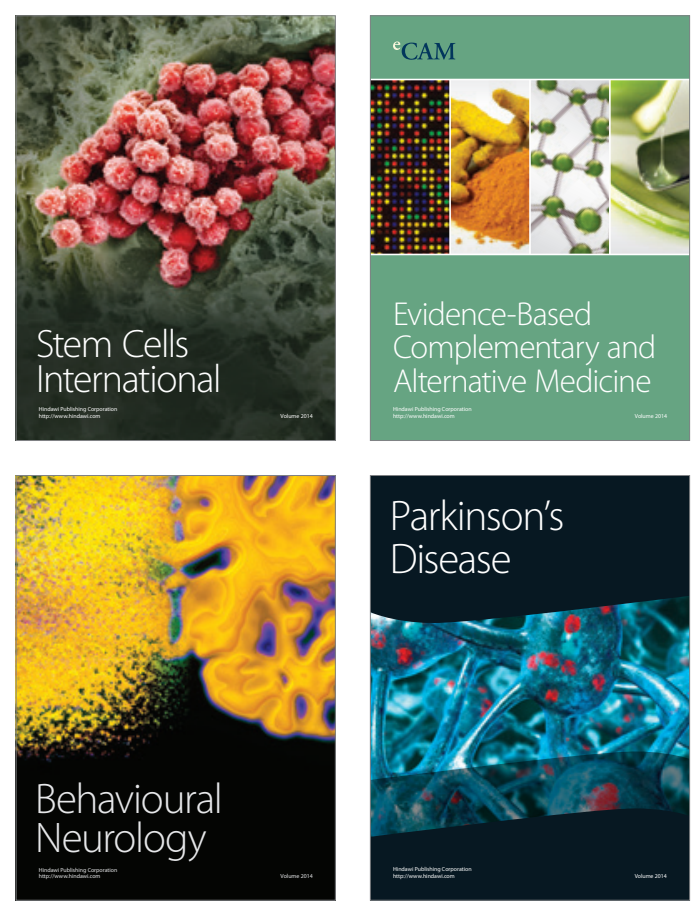

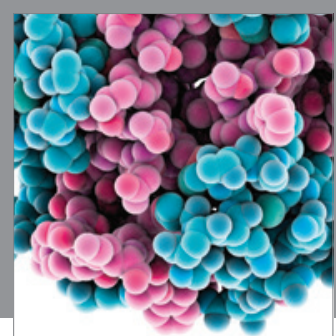

Journal of
Diabetes Research

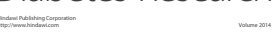

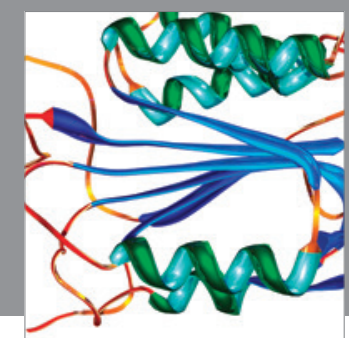

Disease Markers
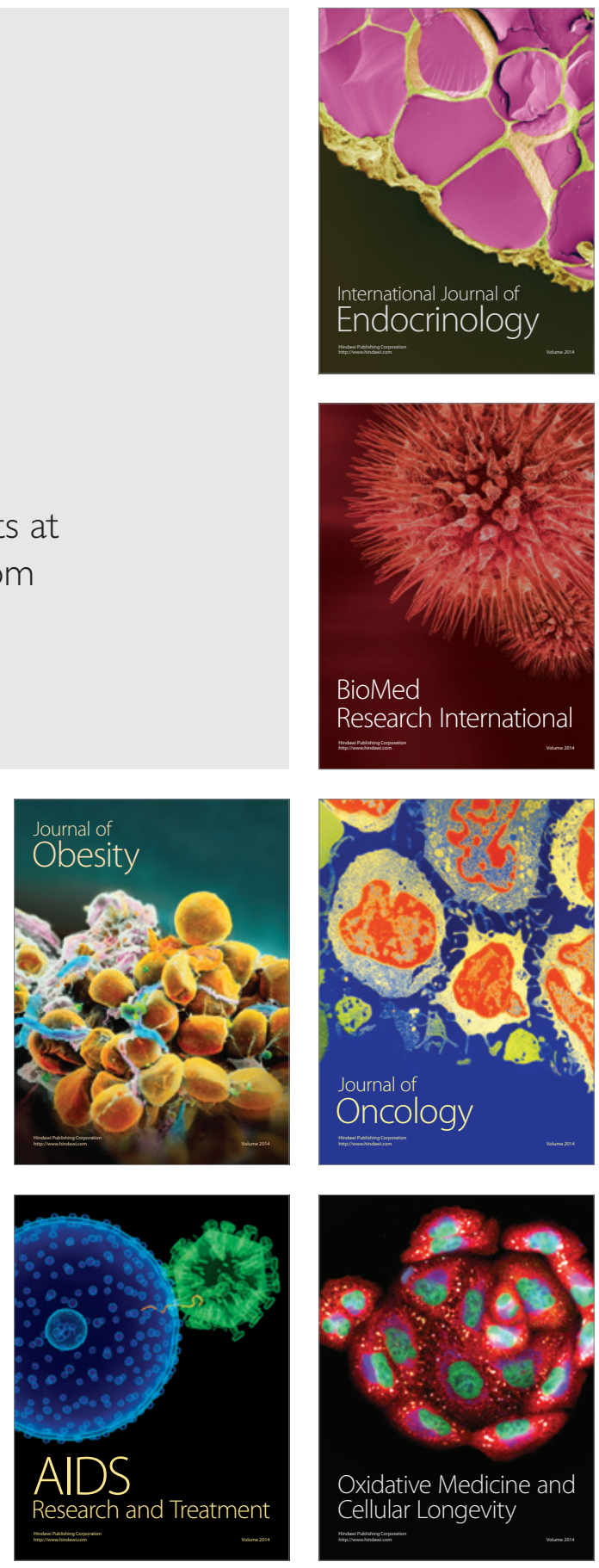